Check for updates

Cite this: RSC Adv., 2020, 10, 18180

\title{
Recent advances in catalytic chain transfer polymerization of isobutylene: a review
}

\begin{abstract}
Tota Rajasekhar, (D) * Gurmeet Singh, Gurpreet Singh Kapur* and S. S. V. Ramakumar
This review presents the development of highly reactive polyisobutylene (HRPIB), a major commercial intermediate toward fuel and lubricant additives. Recent years have witnessed very substantial advances in the catalytic chain transfer polymerization (CCTP) of isobutylene/industrial Raffinate-1 (C4 Raffinate) to produce HRPIB, particularly in nonpolar solvents at elevated temperatures. The main subjects of this review are cationic polymerization of isobutylene, progress in HRPIB research and existing challenges, and recent advances of CCTP. New initiating/catalyst systems based on ionic liquids with Lewis acids are detailed, and this approach may open new views in the synthesis of HRPIB. Some current developments in CCTP of industrial Raffinate-1 and mechanistic studies are also described. This review strongly supports that the hydrocarbon soluble Lewis acid·ether (LA·ether) complex catalyzed CCTP will become the most popular technique for preparing HRPIB and could replace the traditional $\mathrm{BF}_{3}$ catalyzed

industrial method.
\end{abstract}

Received 29th February 2020

Accepted 30th April 2020

DOI: $10.1039 /$ dOra01945c

rsc.li/rsc-advances

\section{Introduction}

In general, sludge, soot, oxidation products, and other deposit precursors are generated in engine oil during operation of an engine, which could be due to the incomplete oxidation/ combustion of fuel. These incomplete combustion byproducts cause corrosion, deposit formation, and wear within the engine over time, which directly affects engine performance. To avoid this, additives are typically added to lubricating motor oils. ${ }^{1}$ Furthermore, the engine performance could be increased by formulating engine oil with dispersants, antioxidants, viscosity modifiers and pour point depressants. ${ }^{2}$ Usually, formulated engine oil consists of $\sim 15 \mathrm{wt} \%$ of additives with major composition of dispersants, which are $\sim 50 \mathrm{wt} \%$ of the total additive percentage. Since 1950s, dispersants have been used in engine oils. Dispersants are composed of a polar head group and an oil soluble non-polar tail parts. The dispersant is adsorbed on to the surface of ultra-fine particle sized soot surface due to polar interactions, which avoids agglomeration of the particles by suspending in the form of micelles in the oil. ${ }^{1,2}$ This has been schematically represented in Fig. 1.

Dispersants are amphiphilic polymers possessing nonpolar, hydrocarbon chain and a polar moiety/chain at the chain end. Different types of dispersants are being typically used by the oil additive industry; for instance polyalphaolefins; polyisobutylene (PIB) and polypropylene, and acrylate-based polymers. PIB exhibits low ceiling temperature, $175^{\circ} \mathrm{C}$, which is an important characteristic of PIB that makes it well appropriate

R\&D Center, Indian Oil Corporation Limited, Sector-13, Faridabad-121007, Haryana, India.E-mail: rajasekhart@indianoil.in; kapurgs@indianoil.in for the use of as ashless dispersants. Moreover, cationic polymerization is used to synthesize PIB component of dispersants. Polyisobutylene succinimide (PIBSI) dispersants are of the most common ashless dispersants used in engine oil, which have been initially developed by Le Suer and Stuart. ${ }^{3,4}$ The PIBSI dispersants are prepared in two steps. In the first step, PIB chain terminated with succinic anhydride (PIBSA) is generated mostly via Alder-ene reaction. Then, PIBSA is reacted with a polyamine to produce PIBSI dispersants (Scheme 1). In comparison to internal olefin ends (tri and tetra substituted) containing PIBs (conventional PIBs), PIB with terminal vinylidene functionality (exo group) is highly reactive toward maleic anhydride ${ }^{5-9}$ to give PIBSA. Because of the higher reactivity for post-polymerization reaction, exo group containing PIB is termed as highly reactive polyisobutylene (HRPIB).

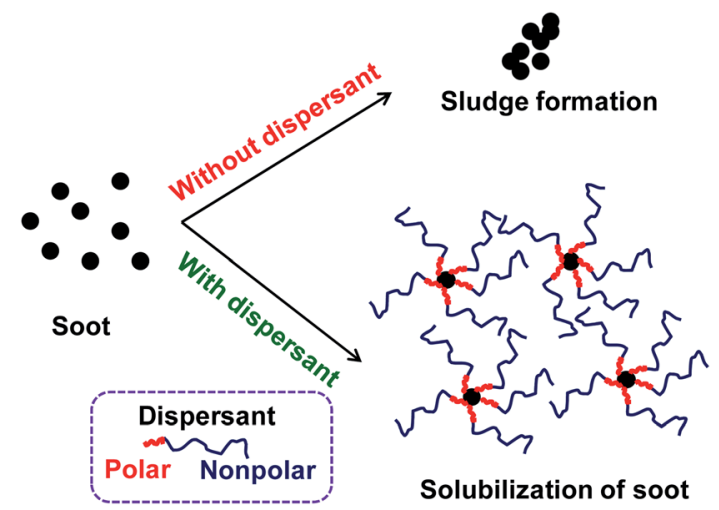

Fig. 1 Schematic representation of role of dispersants in engine oil. 


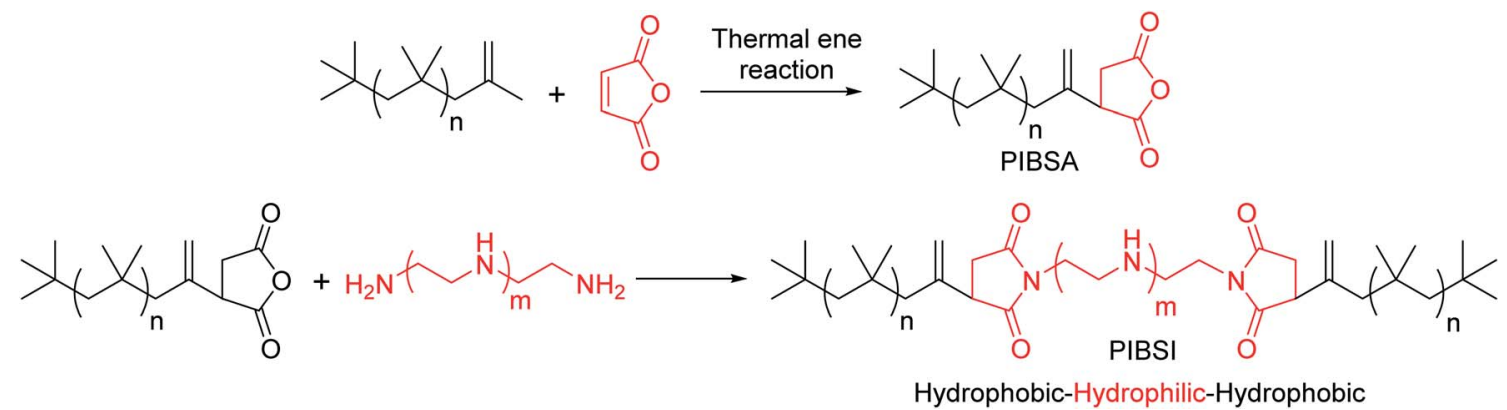

Scheme 1 Preparation of PIBSI from precursor, HRPIB.

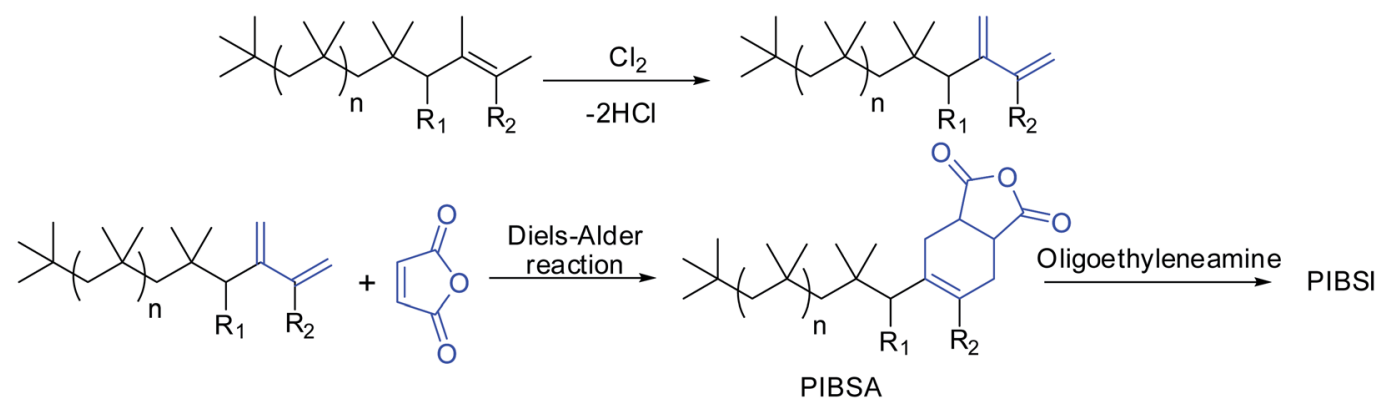

Scheme 2 Preparation of PIBSI by using conventional PIB.

Conventional PIBs have low reactivity for further postpolymerization functionalization due to steric crowding of the internal double bond. ${ }^{10-13}$ Earlier, the conventional PIBs required to chlorination followed by dehydrochlorination to react with maleic anhydride to give PIBSA, which was further reacted with oligo-alkylenimines to form PIBSI dispersants (Scheme 2) ${ }^{14-17}$ The main disadvantage of this method was that resulting dispersants contain residual chlorine as organic chlorides and also produces large quantities of chlorine containing waste water, which is the major environmental concern. Thus, HRPIB is the most preferred precursor for the preparation of ashless dispersants.

More than 750000 metric tons of HRPIB, PIBs with terminal double bonds (exo bonds) are produced each year. Exxon, Amoco, $\mathrm{BP}$, and BASF are globally major manufacturers of HRPIB. Dispersant properties are significantly affected by the molecular weight of polymer. Based on the molecular weight, PIB market size is divided into low molecular weight $\operatorname{PIB}\left(M_{\mathrm{n}}<5000 \mathrm{~g} \mathrm{~mol}^{-1}\right)$, medium molecular weight PIB $\left(M_{\mathrm{n}}=10000-100000 \mathrm{~g} \mathrm{~mol}^{-1}\right)$ and high molecular weight PIB $\left(M_{\mathrm{n}}>100000 \mathrm{~g} \mathrm{~mol}^{-1}\right)$. Viscosity is an important physical parameter to differentiate low, medium and high molecular weight HRPIBs. Viscosity of the low molecular weight HRPIB for $M_{\mathrm{n}}=1000 \mathrm{~g} \mathrm{~mol}^{-1}$ is approximately 200 centistokes (cSt) at $100{ }^{\circ} \mathrm{C}$, which is significantly lower than the viscosity of medium and high molecular weight HRPIBs. Amongst them, low molecular weight HRPIB is the most important class because of their demanding as lubricant and fuel additives. Low molecular weight HRPIB, 1000-2500 $\mathrm{g} \mathrm{mol}^{-1}$ with polydispersity index of 2-3 are used as the additives..$^{18,19}$

In the past 10 years, substantial advances in synthesis of commercially valued, HRPIB via different cationic polymerization approaches have been achieved. ${ }^{20-50}$ In particular, the catalytic chain transfer polymerization (CCTP) in nonpolar solvents using Lewis acid·ether complexes (LA·ether), has recently recognized much interest in the view of their industrial relevance..$^{27-50}$ Because the recent CCTP embodies attractive features compared to the traditional $\mathrm{BF}_{3}$ catalyzed polymerization method, ${ }^{51,52}$ such as the simple experimental operation and cost, tolerance of ambient reaction conditions, and applicability of various kinds of reactor systems. ${ }^{19,53,54}$ To date, low molecular weight HRPIB is the most important industrial precursor material in the preparation of motor oil and fuel auxiliaries.

The endeavour of this perspective is clearly illustrated in Fig. 1 and Scheme 1, which presents importance and motivation on behind in the development of HRPIB. We will first briefly discuss the existing synthetic methods of engine oil/lubricant dispersant precursor and challenges. Subsequently, we will also review the basics of isobutylene cationic polymerization, and conventional \& living polymerization of isobutylene approaches towards in development of HRPIB. This review finally covers the recent progress in CCTP of isobutylene/industrial Raffinate-1 feed for HRPIB synthesis and shows advantages of this method in comparison to conventional polymerization method. Furthermore, fundamental mechanistic aspects of chain transfer agent involved cationic polymerization will also be focused. Development of new initiating system and cost-effective processes for the production of HRPIB is currently an active area of research in academics and industry. An interested reader can consult previous reports on various developments in cationic polymerization of isobutylene..$^{55-60}$ 


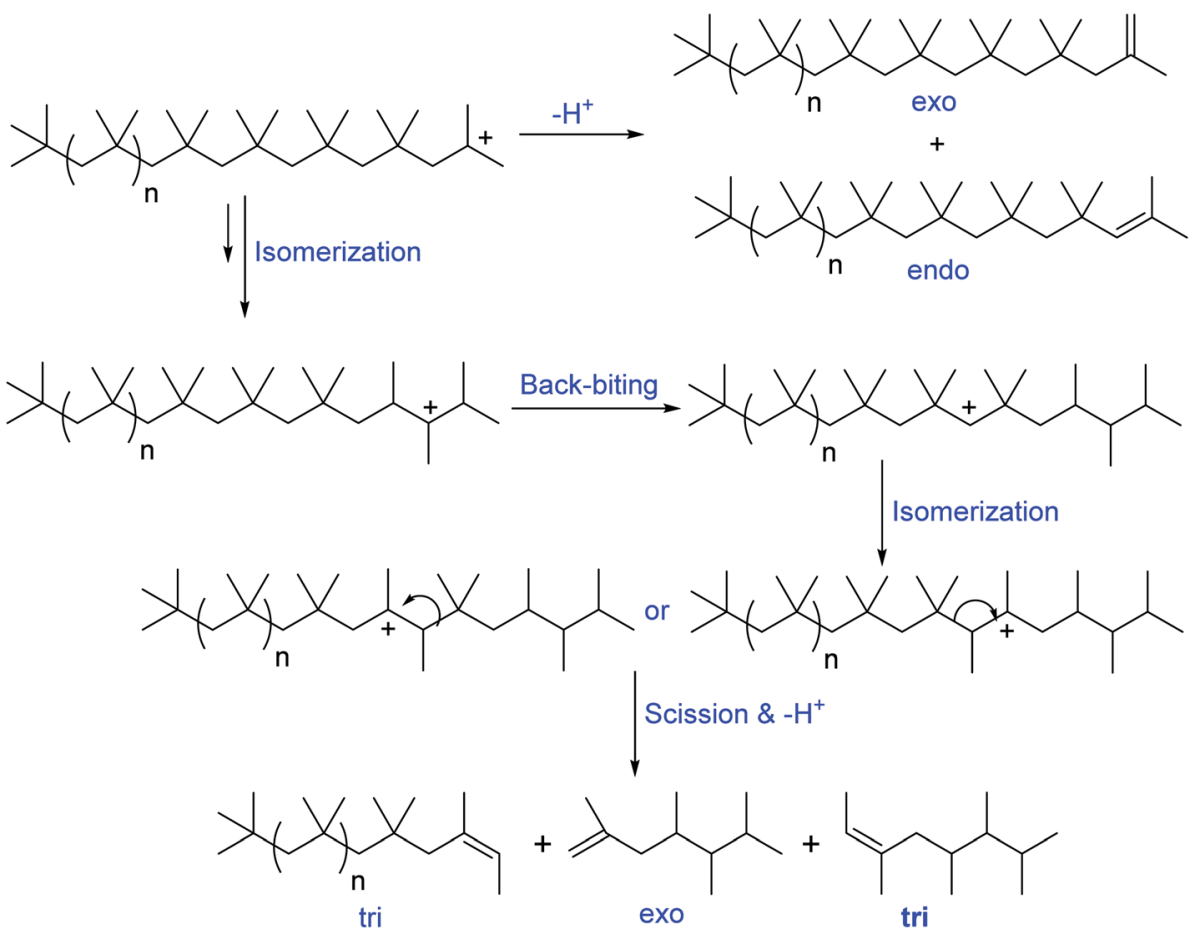

Scheme 3 Mechanism of formation of different olefinic groups in the conventional cationic polymerization of isobutylene (proposed by Faust et $\left.a{ }^{65}\right)$.

\section{Synthesis of engine oil/lubricant dispersant precursor and challenges}

Oil additive industry typically use PIB based dispersants, due to their unique properties of cleaner burning, low toxicity, good thickening properties, high shear stability, water and oxidation resistance, tackiness, and cohesive strength. Moreover, PIB based dispersants possess various other value-added advantage including less char formation at high temperature performance conditions and ability to improve final lubricant and fuel performance. Basically the precursors of PIB dispersants consist of olefinic group/double bond. Based on the double bond position, the PIB precursors are broadly classified in to two categories: (i) conventional PIB consists of internal double bonds (tri and tetra substituted olefinic groups), and (ii) HRPIB consists of external double bond (exo olefinic group).

The internal double bonds containing PIB preparation with low molecular weight has been well known as conventional process/Exxon process. In this process, isobutylene polymerization in the presence of cationogen and Lewis acid, $\mathrm{AlCl}_{3}$ or $\mathrm{EtAlCl}_{2}$ as coinitiator produces the low molecular weight conventional PIB. ${ }^{61-64}$ Importantly, the reaction mechanism of conventional PIB preparation is associated with a complex set of isomerisation and chain scission reactions. Faust et al., clearly demonstrated that the formation of "conventional" PIBs with internal tri- and tetra-substituted olefinic groups (Schemes 3 and 4) through complex mechanism of the carbocationic rearrangements. ${ }^{65}$ Here, the internal olefins formation in the polymerization of IB has been understood by ionization of PIB-Cl to $\mathrm{PIB}^{+}$using $\mathrm{EtAlCl}_{2}$ in the presence of a proton trap.
A possible mechanism has been proposed by Faust et al., to explain the olefin structures. The mechanism involving a sterically hindered cation arising via hydride and methyde shifts from the chain growing $\mathrm{PIB}^{+}$. Tri-substituted olefins form through a distant hydride shift by backbiting followed by a methyde shift and chain scission of the $\mathrm{PIB}^{+}$. Moreover, the tri-substituted olefins possess of irregular carbon numbers, which clearly supports the chain scission pathway in the mechanism (Scheme 3). But the exo- and endo olefins are formed by simple $\beta$-proton elimination from the $\mathrm{PIB}^{+}$.

The formation of exo-, endo-, and tetra-substituted olefins was found accidentally, which form under milder conditions. The ionization of PIB-Cl at room temperature in the absence of

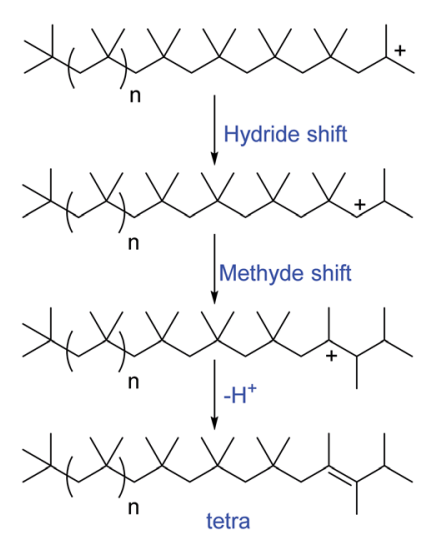

Scheme 4 Mechanism of formation of internal olefinic group, tetra substituted olefin in the conventional cationic polymerization of isobutylene (proposed by Faust et al. ${ }^{65}$ ). 


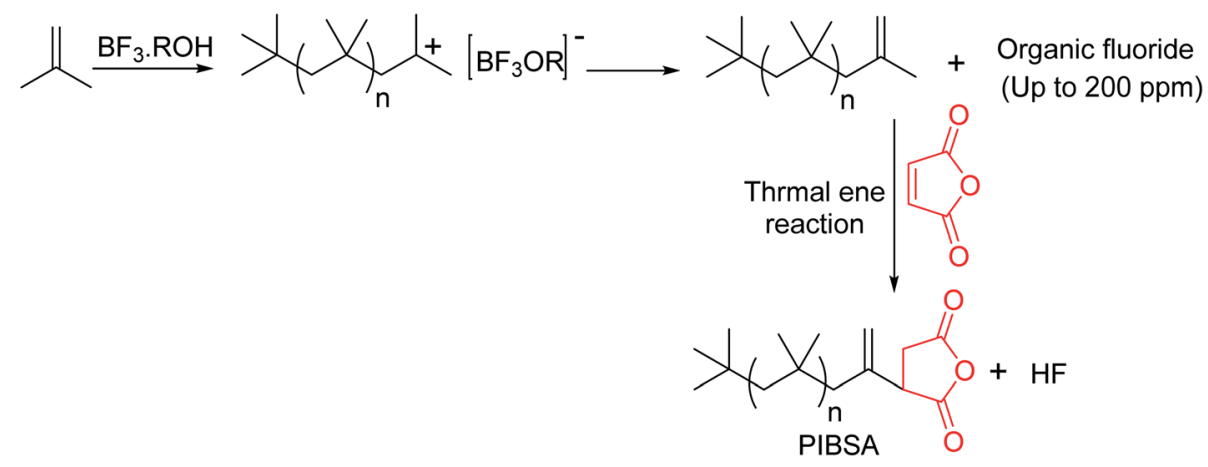

Scheme 5 Schematic representation of formation of byproduct in traditional HRPIB synthesis process.

a proton trap resulted to the formation of these three olefins. As shown in Scheme 4, $\mathrm{PIB}^{+}$undergoes to hydride and methyde shifts followed by proton elimination, which results to tetrasubstituted olefins. ${ }^{65}$

The external double bond containing PIBs (HRPIB) readily react with maleic anhydride, ${ }^{5}$ which clearly indicates that chlorination followed by dehydrochlorination is not essential to prepare PIBSA from HRPIB. Importantly, HRPIB route is environmental friendly one for the manufacture of ashless dispersants. Cationic polymerization of IB initiated by $\mathrm{BF}_{3}$ complex with either alcohol or ethers as catalyst system is the traditional process, to prepare commercial low molecular weight HRPIBs with more than $80 \mathrm{~mol} \%$ of exo-olefin content. The process was first developed by BASF and is more commonly known as BASF process. ${ }^{66,67}$ Major drawback of this process is the critical low polymerization temperature, because of the requirement of low temperatures and highly purified feed making the process more expensive. Another disadvantage of this process is that usage of $\mathrm{BF}_{3}$ catalyst system produces fluorine based byproducts (Scheme 5). These fluorine based products, under the thermal stress, get converted to highly corrosive hydrogen fluoride. Moreover, in this process the fluorine content in HRPIB is noticed up to $200 \mathrm{ppm} .{ }^{54}$ Furthermore, researchers have been trying different ways to produce HRPIB with the aim to replace $\mathrm{BF}_{3}$ catalyst used in the traditional process.

In the recent years, significant contributions have been made by industries and academic-industrial collaborations for developing new catalyst systems and improvising process for producing HRPIB. ${ }^{20-54}$ Before going to discuss about the insights in development of HRPIB research, a summary is given below on historical developments in cationic polymerization of isobutylene. These past findings have been actually shown the route map to commercial valued HRPIB developments.

\section{Cationic polymerization of isobutylene}

Cationic polymerization offers the best existing methodology for the homopolymerization and copolymerization of isobutylene, which cannot be polymerized by any another polymerization method. ${ }^{68-70}$ Free radical polymerization of inactive double containing monomers (ethylene, propylene, isobutylene, etc.) requires extremely high pressure $(>1000$ bar) and temperatures $\left(>150{ }^{\circ} \mathrm{C}\right)$. This is because of high activation energy of the free radical polymerization of the inactive monomers. ${ }^{71,72}$ However, under the certain polymerization conditions, the formed low molecular weight PIB chains can undergo depolymerization and regenerates isobutylene by backward reaction. Thus, scientific community does not show interest in free radical polymerization of isobutylene. Anionic polymerization of isobutylene can't be observed, due to the low reactivity of isobutylene with anionic species/initiator. The cationic polymerization is initiated by a cationic initiator (for example $t$ butyl chloride) in conjunction with a Lewis acid (LA), where heterolytic bond cleavage of the initiator leads to reactive cation species and counter anion. In the subsequent step, the cation species reacts with isobutylene to yield a cationic-adduct. Propagation involves the repetitive addition of isobutylene to the growing carbenium ion until a chain-breaking reaction via chain transfer or termination occurs. ${ }^{73-81}$ In the chain transfer step, exo, endo, tri and tetra substituted double bond containing PIBs are formed by a complex set of isomerisation and chain scission reactions followed by proton elimination of the propagating $\mathrm{PIB}^{+}$. In the presence of a chain transfer agent, chain transfer reactions predominantly involve $\beta$-proton elimination to form exo end groups. Adding ethers as the chain transfer agent has been found to be effective to improve the

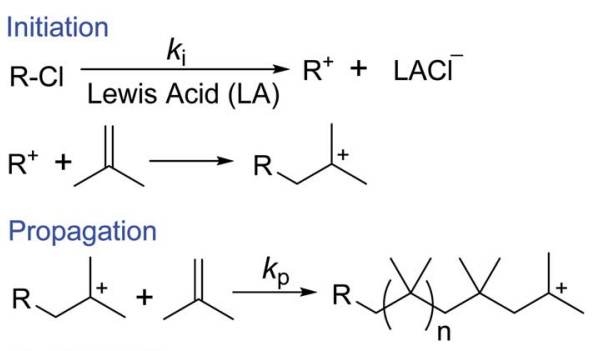

Chain transfer
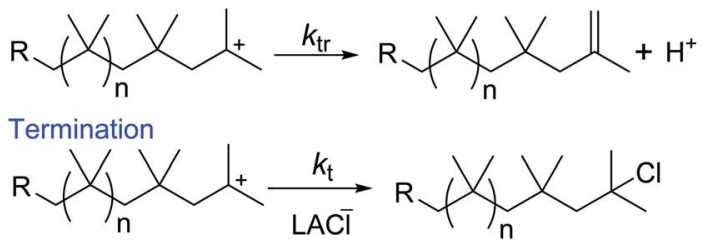

Scheme 6 Schematic representation of steps involved in cationic polymerization of isobutylene. 
controllability to form exo-olefin end groups. ${ }^{38-50}$ These developments are clearly discussed in the next section: development of HRPIB synthesis. Additionally, the molecular weight of the polymerization can be limited by chain transfer. In the termination step $\mathrm{PIB}^{+}$cations usually undergo ion collapse by transferring of an anionic fragment from the complex counterion. In the present illustration (Scheme 6), $\mathrm{PIB}^{+}$cation is converted to PIB-Cl by ion collapse in the termination step.

Interestingly, overall activation energy of the isobutylene polymerization is negative, and increase in temperature causes decrease in the rate of propagation of polymerization. ${ }^{34,74}$ The activation energy can be expressed by the following equation.

Activation energy of polymerization $=$ (sum of activation energies of initiation and propagation) - (activation energy of termination or chain transfer)

The above equation is a fundamental statement for activation energy of polymerization. In the case of chain transfer polymerization, activation energy of termination could be replaced by activation energy of chain transfer. ${ }^{71}$ In the above equation, the sum of activation energies of initiation and propagation is always smaller than activation energy of chain transfer. Increase in polymerization temperature leads to shorter polymer chains, which is due to overcoming the energy barrier for the chain transfer reaction. ${ }^{34,76-81}$ This fundamental aspect helps in controlling the molecular weight of oil and lubricant additives during their synthesis. Moreover, chain transfer step plays a significant role in HRPIB synthesis, ${ }^{\mathbf{2 0}-50}$ which could be discussed on detail in the following sections.

Cationic polymerization of isobutylene has a long story, the first report of the isobutylene polymerization by acid initiation at room temperature was revealed in 1873, where the polymerization was restricted to formation of low molecular weight PIB oligomers. Since then, polymerization reactions of various conditions were examined, ${ }^{\mathbf{8 2}-\mathbf{8 4}}$ for which several types of catalyst systems have been developed to prepare high-molecular weight PIB. ${ }^{\mathbf{8 5}, 86}$ The discovery of butyl rubber/synthetic rubber in early 1900s brings cationic polymerization into light. In the initial reports recognized that low temperatures and $\mathrm{AlCl}_{3}$ as catalyst have been required to obtain high molecular weight PIBs. Even though achieving of the molecular weight is more than $100000 \mathrm{~g} \mathrm{~mol}^{-1}$, the polymer was not used for practical end use application. Later, the issue was overcome by copolymerization of isobutylene with isoprene. Here, the unsaturation unit of isoprene could be used for vulcanization of copolymer, butyl rubber in the formulation process. The discovery of butyl rubber led to in detail understanding of cationic polymerization. ${ }^{87}$ Control in cationic polymerization was lagging because of thermodynamically favoured chain transfer reaction. It was well known that chain transfer could be suppressed by lower temperatures, which favours higher molecular weight polymer. Based on these Kennedy et al., the conditions for the "quasiliving" polymerization of isobutylene have been realized. ${ }^{\mathbf{8}}$ Moreover, the polymerizations having controlled initiation and the absence of termination or chain transfer during the propagation. These understandings gave direction for the controlled synthesis of low molecular weight PIBs having distinct end groups with predictable molecular weight. PIB of low molecular weights are valuable viscosity modifiers, fuel and lubricating oil additives. ${ }^{\mathbf{8 9 - 9 1}}$ Relevant for this review are the currently practiced "conventional" and "living" cationic polymerizations of isobutylene as well as end group functionalities derived there from. The present review focused on chain end olefinic functionality of low molecular weight $\left(<5000 \mathrm{~g} \mathrm{~mol}^{-1}\right)$ isobutylene-based polymers.

Conventional polymerization of isobutylene. Initially, commercially important low molecular weight PIB was developed under uncontrolled conditions, where proton elimination predominates and results to olefinic terminal end. ${ }^{92}$ Lewis acids are being used as catalysts in these conventional polymerizations. ${ }^{93,94}$ High yields of tri and tetra olefinic end groups are obtained with the conventional Lewis acid catalyzed polymerizations. By addition of chain transfer agents in the polymerization system led to $70-90 \%$ of the chain ends with exo olefin group, ${ }^{28-50}$ and the polymerization named as catalytic chain transfer polymerization (CCTP). BASF has been marketing the HRPIB having exo content $\sim 80 \%$, under the trade name Glissopal® using this CCTP. Moreover, these commercial developments are origin for the CCTP. In detail development of the HRPIB process using CCTP will be discussed in the following sections.

Living/quasiliving polymerization of isobutylene. Kennedy's group initially started the development toward "living" isobutylene polymerization. Initially it was developed by using bifunctional initiator-transfer agent systems, and co-initiated with boron trichloride $\left(\mathrm{BCl}_{3}\right)$. After that, witnessed the dynamic development of the field of living cationic polymerization systems of isobutylene. Living polymerizations, which progress in the absence of chain transfer reactions/termination, and reaction rates, were too high for sufficient synthetic control. Termination of these cationic polymerizations always led to tertchloride chain ends, and this led to the realization that electron donating species complex with Lewis acids in situ. The living cationic polymerization in the presence of electron donating species is due to a dynamics of equilibrium between dormant and active species via onium ion. ${ }^{95}$ It can be supported with recent study by Faust et al. ${ }^{34}$ that the formation of dynamic equilibrium in between carbenium ions (active species) from oxonium ions (dormant species) was evidenced by using model experiments. It has been also found that the addition of common ion salts to cationic polymerization leads to a living polymerization. For example, the addition of tetraalkylammonium salt results to living polymerization, where it favours an appropriate equilibrium between the active and dormant species. ${ }^{96-98}$ Further it could be believed that nonliving polymerization proceeds through free ions path way. After these observations researchers showed that common ion salts and electron donating species have the same general effect on polymerization control by suppressing the generation of free ions via the formation of suitable common counter ions. For Lewis bases such as substituted pyridines, this controlled polymerization easily occurs through the scavenging of protic 
impurities or water in the system, which has the added benefit of suppressing protic initiation. The two most commonly used Lewis acid catalysts for quasiliving isobutylene polymerizations are $\mathrm{TiCl}_{4}$ and $\mathrm{BCl}_{3}{ }^{99,100}$ Of these, $\mathrm{TiCl}_{4}$ has received the most attention due to its usefulness in the synthesis of block copolymers via sequential addition of monomers. ${ }^{101,102}$ As an alternative, aluminum based catalysts have been explored. ${ }^{\mathbf{1 0 3 - 1 0 5}}$ Faust et al. made further use of aluminum alkyl halide catalysts by using methyl aluminum bromides for quenching reactions with butadiene. These sequential attempts and findings have showed an initial direction in development of HRPIB.

\section{Development of HRPIB synthesis}

In recent decades, numerous new methods for the synthesis of HRPIB have been reported. Broadly three approaches on independently for the synthesis of HRPIB are being developed: (i) through living cationic polymerization (ii) using solvent-ligated complexes and (iii) modified conventional cationic polymerization or CCTP. The basic developments in the three approaches are shorted out here.

Living cationic polymerization approach. Mono and difunctional exo-olefin terminated PIB synthesis has been primary reported by Kennedy et al. ${ }^{\mathbf{1 0 6 - 1 0 9}}$ This process involved first the synthesis of PIB-Cl using difunctional initiator and co-initiator, $\mathrm{BC}_{3}$ in $\mathrm{MeCl}$ at $-50{ }^{\circ} \mathrm{C}$. In the following step PIB-Cl is converted in to HRPIB by refluxing with $t$-BuOK in THF. The seminal work on nucleophilic addition of PIB-Cl has been illustrated by Kennedy. ${ }^{110-113}$ Here was found that the addition of around 2 fold molar excess of allyltrimethylsilane and $\mathrm{TiCl}_{4}$ to a living $\mathrm{BCl}_{3}$ coinitiated polymerization of isobutylene produced a quantitative yield of allyl terminated PIB. Several groups have reported analogous reaction method for the synthesis of HRPIB by addition of methallyltrimethylsilane. ${ }^{\mathbf{1 1 4 - 1 1 6}}$ However, there is a drawback to adopt this process at industrial level, because of high cost of the silane agents, which could also be used in excess with respect to the chain ends. Storey et al. prepared PIB-Cl using living cationic polymerization at $-80{ }^{\circ} \mathrm{C}$ with $\mathrm{TiCl}_{4}$, which was then end quenched with deliberate addition of sterically hindered amines to produce HRPIB. ${ }^{117}$ However, strongly basic tertiary and secondary amines form a mode of interaction with $\mathrm{TiCl}_{4}$ and gives $1: 1$ complexation. Here, the added nucleophilic agent is more likely to be rapidly consumed by interaction with the Lewis acid rather than reacting with the carbenium ion chain ends. The result is ion-pair collapse and production of unmodified PIB-Cl. While in the case of sterically hindered amines, uncomplexed base with $\mathrm{TiCl}_{4}$ is responsible for the exo olefin formation at the carbenium ion chain end. Later on found that the most effective classes of quenchers are sulfides and ethers. ${ }^{20}$ It has been projected to use sulfides or ethers as quenchers instead of hindered bases. In this case, the quenching proceed into two steps through the formation of stable sulfonium or oxonium PIB ions, which followed by decomposition of resulting onium ions by addition of excess of nucleophile to yield HRPIB. ${ }^{\mathbf{2 0 - 2 2}}$ Main disadvantages with these imitating systems are that the reactions have been conducted at low temperatures in chlorinated solvent and expensive reagents have been used for the synthesis. ${ }^{117-119}$
Solvent-ligated complexes catalyzed polymerization approach. Organometallic catalyst is also being used for preparation of HRPIB, where weakly coordination counteranions based on borates, carbonates, alkoxy, and nitrile-ligated metal complexes were used. In the chain transfer step of cationic polymerization, the nature of counteranion shows a major role. In this approach, Mn(II) complexes have been used as initiators by Vierle et al. ${ }^{\mathbf{1 2 0}}$ Zinc-based initiator system was developed by Bochmann et al. to produce HRPIB at room temperature. ${ }^{\mathbf{1 2 1}}$ Kühn et al. investigated HRPIB process using different solventligated complexes with weakly coordination borate or aluminate anions. ${ }^{122}$ Krossing et al. used univalent gallium salts $\left[\mathrm{Ga}\left(\mathrm{C}_{6}\right.\right.$ $\left.\left.\mathrm{H}_{5} \mathrm{~F}\right)_{2}\right]^{+}\left[\mathrm{Al}(\mathrm{ORF})_{4}\right]^{-}$and $\left[\mathrm{Ga}\left(1,3,5-\mathrm{Me}_{3} \mathrm{C}_{6} \mathrm{H}_{3}\right)_{2}\right]^{+}[\mathrm{Al}(\mathrm{ORF}) 4]^{-}$ (where $\mathrm{RF}=\mathrm{C}\left(\mathrm{CF}_{3}\right)_{3}$ ) to achieve synthesis of HR-PIB in different types of solvents. ${ }^{123}$ Voit et al. have reported synthesis of HR PIB using complexes of $\mathrm{Mn}^{2+}, \mathrm{Cu}^{2+}, \mathrm{Zn}^{2+}$, and $\mathrm{Mo}^{2+}$ as catalysts. ${ }^{124}$ The industrial acceptance of this method is difficult due to high cost of the catalyst system and use of chlorinated solvent. This approach has been recently reviewed in detail. ${ }^{57,58}$

Modified conventional cationic polymerization or CCTP approach. Indeed, Kostjuk et al. revealed a simple and proficient initiating system for HRPIB synthesis using cumyl alcohol with $\mathrm{AlCl}_{3} \cdot \mathrm{Bu}_{2} \mathrm{O} .{ }^{38}$ Actually, this new imitation system has been originated, during systematic studies of the controlled cationic polymerization of styrene using complexes of $\mathrm{TiCl}_{4}$ or $\mathrm{AlCl}_{3}$ with ethers as initiating system. ${ }^{\mathbf{1 2 5 - 1 2 8}}$ Based on these studies, very high molecular weight polystyrene was obtained using living cationic polymerization of styrene with $\mathrm{CumOH} / \mathrm{AlCl}_{3} \cdot \mathrm{Bu}_{2} \mathrm{O}$. But, lower molecular weight PIB has been obtained during cationic polymerization of isobutylene with the same initiating system. Luckily, the PIB terminal ends having exo end groups. Similar type of initiating system for HRPIB synthesis was reported, independently by $\mathrm{Wu}$ and co-workers. ${ }^{36,37}$ But, high activity and regioselectivity of the polymerization are achieved only in a polar solvent (dichloromethane) and toluene, whereas a number of limitations are observed in non-polar ( $n$-hexane). These findings encouraged the intensive investigations of Lewis acid-ether complexes for HRPIB synthesis. New catalyst systems, $\mathrm{FeCl}_{3}$-ether and $\mathrm{GaCl}_{3}$ - ether complexes have been investigated by Faust et al. ${ }^{42}$ These initialing systems could be used in conjunction with $t$-alkyl chlorides, which is due to the chlorophilic nature of $\mathrm{FeCl}_{3}$ and $\mathrm{GaCl}_{3}$. Interestingly, the cationic polymerization of isobutylene with these initiating systems observed at high rate with exo content $\sim 80 \%$. Moreover, the first-order plots are curved downward, which could be due to poor solubility of protonated complex salt. Very recently, this precipitation issue has been overcome by employing alkylaluminum dichloride $\left(\mathrm{EtAlCl}_{2}\right.$, i-BuAlCl$\left.{ }_{2}\right)$ ether complexes as catalysts in the CCTP. ${ }^{27-35}$ Faust et al. found that the ethylaluminum dichloride (EADC) · bis(2-chloroethyl)ether (CEE) complex is an effective catalyst, to synthesize the desired HRPIB with high exo-olefin content $(\sim 90 \%)$ at high reaction temperatures $\left(0-20{ }^{\circ} \mathrm{C}\right)$ in non-polar solvents. ${ }^{30,31}$ Furthermore, CCTP of C4 feed (industrial Raffinate-1) using $t$-BuCl/EADC - CEE initiating system has been systematically studied recently. Here, the presence of other $\mathrm{C} 4$ olefins in copolymerization mixture affected the nature and distribution of olefin types in HRPIB. Moreover, the 

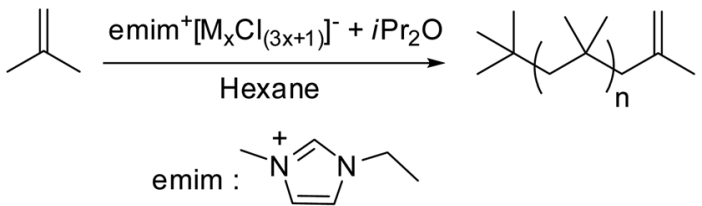

$\mathrm{M}: \mathrm{Al}, \mathrm{Ga}, \mathrm{Fe}$

$X: 1,2$

Scheme 7 lonic liquid catalyzed cationic polymerization of isobutylene.

copolymerization has been evaluated under simulated steady state conditions in a CSTR reactor in the presence of exo enhancer. These recent findings will be discussed on detail in the following section.

\section{Recent developments in CCTP of isobutylene for HRPIB}

New initiating/catalyst systems. In order to advance development of the CCTP for synthesis of HR PIB, the new catalytic system based on an acidic chloroaluminate ionic liquid, 1-ethyl-3methylimidazolium chloride-aluminum trichloride (emimCl$\mathrm{AlCl}_{3}$ ) in combination with ether has been introduced by Kostjuk et $a .^{48}$ Moreover, ionic liquids are promising for different industrial applications due to their thermal and chemical stability. Previous to this study, the cationic polymerization of isobutylene using the ionic liquid-based catalyst has been described only in a patent literature, where provided of limited information. ${ }^{\mathbf{1 2 9 - 1 3 2}}$ Particularly, there is no information about the molecular weight distribution and chain end structure of the synthesized oligomers is available. Here, Kostjuk et al. exceptionally found that high exoolefin end group content $(\geq 90 \%)$ and a relatively narrow molecular weight distribution $\left(M_{\mathrm{w}} / M_{\mathrm{n}} \leq 2.0\right)$ with emimCl- $\mathrm{AlCl}_{3}$ initiating system. In terms of polymerization rate, polymerization of isobutylene with the emimCl- $\mathrm{AlCl}_{3} / \mathrm{iPr}_{2} \mathrm{O}$ initiating system is relatively lower rate in comparison with $\mathrm{RAlCl}_{2} \cdot$ ether systems. This could be due to proceeding of polymerization in heterogeneous pathway at the interface of ionic liquid catalyst particles due to the insolubility of these polar species in $n$-hexane. This was evidenced by conducting of the polymerizations under ultrasonication conditions. The reaction rate increased significantly when the reaction mixture has been ultrasonicated before beginning the polymerization, due to decrease of the particle size of ionic liquid. Furthermore, the content of the exo-olefin content and PDI are not affected by the ultrasonication (Scheme 7).

Later on Kostjuk et al. in their successive work, to solve the problem of slow polymerization with emimCl-AlCl $\mathrm{Almitating}_{3}$ system, they have studied the influence of ionic liquid acidity, nature of Lewis acid and imidazolium salt on the reaction rate. ${ }^{49}$ In this work, various Lewis acids $\left(\mathrm{AlCl}_{3}, \mathrm{AlBr}_{3}, \mathrm{iBuAlCl} \mathrm{Al}_{2}, \mathrm{FeCl}_{3}\right.$, $\mathrm{GaCl}_{3}$ and $\mathrm{BBr}_{3}$ ) have been used for the preparation of acidic ionic liquids by the reaction with imidazole chloride, and their activity in isobutylene polymerization were examined. High exo content and relatively narrow PDI have been obtained only with emimCl-AlCl ${ }_{3}$, emimCl-FeCl ${ }_{3}$ and emimCl- $\mathrm{GaCl}_{3}$. Moreover, the polymerization rate depended on the rate of partial hydrolysis of ionic liquid and increased in the following order: emimCl-FeCl $\mathrm{F}_{3}<$ emimCl- $\mathrm{GaCl}_{3}<$ emimCl-AlCl $\mathrm{Al}_{3}$. For efficient synthesis of HRPIB, the ionic liquid based catalyst needs to be soluble at polymerization temperature, and possess high Lewis acidity. HRPIB with targeted molecular weight, PDI and high exo content was achieved emimCl- $\mathrm{FeCl}_{3}$, due to low selectivity to emimCl- $\mathrm{FeCl}_{3}$ : ether ratio. But sonication of polymerization mixture has been required to get high polymerization rate, due to poor dispersion of emimCl- $\mathrm{FeCl}_{3}$ in $n$-hexane. The main disadvantage of previously developed initiating systems of CCTP is relatively high PDI of the synthesized HRPIB, which is over come with this new system.

Subsequently, titanium tetrachloride, boron trichloride, and ethylaluminum sesquichloride initiating systems in 1-butyl-3methylimidazolium hexafluorophosphate $\left([\mathrm{Bmim}]\left[\mathrm{PF}_{6}\right]\right)$ ionic liquid have been studied by $\mathrm{Wu}$ and co-workers. ${ }^{133}$ Initially in this study, $\left[\mathrm{PF}_{6}\right]^{-},\left[\mathrm{BF}_{4}\right]^{-}$, and $\left[\mathrm{NTf}_{2}\right]^{-}$based ionic liquids were screened for their potential in the synthesis of HRPIB. It was shown that $[\mathrm{Bmim}]\left[\mathrm{PF}_{6}\right]$ is the best ionic liquid for polymerization of isobutylene at $-10{ }^{\circ} \mathrm{C}$ using an $\mathrm{H}_{2} \mathrm{O} / \mathrm{TiCl}_{4}$ initiating system, and it was a suspension polymerization. In this study, HRPIB with a high exo-olefin end group content (>80\%) was obtained. Furthermore, the exo content is relatively higher in the ionic liquid $\left([\mathrm{Bmim}]\left[\mathrm{PF}_{6}\right]\right)$ than in a polar solvent, dichloromethane, whereas lower $M_{\mathrm{n}}$ of HRPIB with a relatively narrow MWD were obtained in the ionic liquid as compared to polymers obtained in dichloromethane. Density functional theory was used to understand the effects of solvent polarity and ionic structure on the initiating systems and active centre of the polymerization system, and proposed that the polymerization proceeds at the interface of ionic liquid particles. This innovative ionic liquid based catalyst system approach can lead to prospect of new HRPIB technologies. ${ }^{133}$

Copolymerization of isobutylene with other C4 olefins using CCTP. Generally, low molecular weight PIB with internal olefinic groups, i.e. conventional PIB is being produced the industrial scale by using cationic polymerization of industrial Raffinate-1. But the polymerization of $\mathrm{C} 4$ mixed feed to yield high exo content polymer is one of major the challenging for industrial HRPIB synthesis. The industrial Raffinate- 1 feed is a composition of different amounts of 1-butene (1B), cis-2butene (C2B), trans-2-butene, and 1,3-butadiene (BD) along with isobutylene. These other olefins are transfer agents and/or terminators, which not only affect the cationic polymerization of isobutylene but also the nature and distribution of olefin types in the final product.

Rajasekhar et al., thoroughly studied copolymerization of isobutylene in the presence of other $\mathrm{C} 4$ olefins (1B, C2B and BD) using EADC.CEE initiating system. ${ }^{\mathbf{5 0}}$ To understand the effect of each of the $\mathrm{C} 4$ olefin on the isobutylene polymerization rate and olefin distribution in the product, the copolymerization of isobutylene with each of the C4 olefins was studied individually. Polymerization of isobutylene in the presence of $1 \mathrm{~B}$ using EADC $\cdot \mathrm{CEE}$ in conjunction with $t$ - $\mathrm{BuCl}$ was studied at $0{ }^{\circ} \mathrm{C}$ with different ratios of [isobutylene] $/[1 \mathrm{~B}]=[95 / 05,90 / 10,80 / 20,70 /$ $30,60 / 40$ and 10/90]. The first order plots with [isobutylene]/ $[1 \mathrm{~B}]>80 / 20$ are linear starting at the origin suggesting 


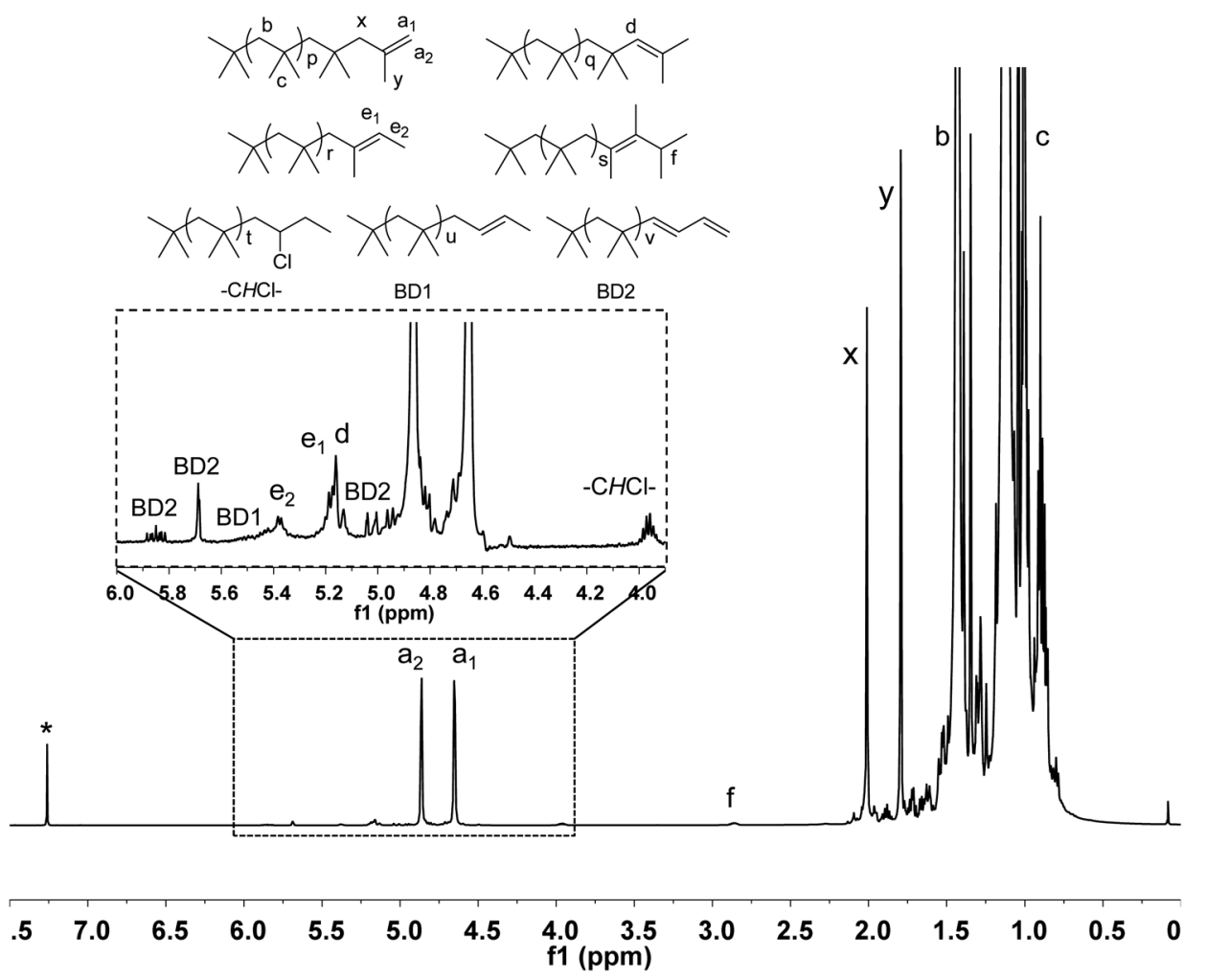

Fig. 2 Typical ${ }^{1} \mathrm{H}$ NMR spectrum of HRPIB obtained by copolymerization of isobutylene.

a constant steady state concentration of the active species. However, the first-order plots are curved downward with [isobutylene $] /[1 \mathrm{~B}] \leq 80 / 20$, suggesting decreasing active species concentration. The ${ }^{1} \mathrm{H}$ NMR spectrum of obtained HRPIB in this study suggested that capping of $\mathrm{PIB}^{+}$with $1 \mathrm{~B}$ gives PIB-1B-Cl due to termination by ion collapse. Noticeable decrease in termination was observed for the polymerization of isobutylene with [isobutylene $+1 \mathrm{~B}$ ] $\geq 2 \mathrm{M}$ up to $8 \mathrm{M}$. The first order plots are moving downward with decreasing [isobutylene]. This suggests that termination has been suppressed at [isobutylene $+1 \mathrm{~B}] \geq$ $2 \mathrm{M}$ relative to propagation. Importantly, determined the reactivity ratio of isobutylene is $r_{\text {isobutylene }}=1100$, which means that isobutylene is 1100 times more reactive than $1 \mathrm{~B}$.

Similarly, polymerization of isobutylene in the presence of C2B with [isobutylene $] /[\mathrm{C} 2 \mathrm{~B}]=92 / 08$, and in the presence of BD with [isobutylene $] /[\mathrm{BD}]=99.5 / 0.5$ and $97.5 / 2.5$ were conducted at different [isobutylene $+\mathrm{C} 2 \mathrm{~B}$ ] $=1,2,4$ and $6 \mathrm{M}$. In addition, the first-order plots are linear when the copolymerization was carried out with [isobutylene $+\mathrm{C} 2 \mathrm{~B}$ or $\mathrm{BD}]>2 \mathrm{M}$.

Polymerization of $\mathrm{C} 4$ olefin mixture, IB : $1 \mathrm{~B}: \mathrm{C} 2 \mathrm{~B}: \mathrm{BD}=$ $43: 28: 4: 0.1$, at $[\mathrm{C} 4$ olefin mixture $]=6 \mathrm{M}$ was also conducted at $0{ }^{\circ} \mathrm{C}$. As similar to isobutylene polymerization with individual other C4 olefin, here the first-order plot is curved downward. Moreover, molecular weights and exo-olefin contents are comparable to those obtained with pure isobutylene.

It has to note that ${ }^{1} \mathrm{H}$ NMR spectrum of HRPIB obtained by polymerization of $\mathrm{C} 4$ feed is more complicated in comparison to synthesized using pure isobutylene. Fig. 2 represents a typical ${ }^{1} \mathrm{H}$ NMR spectrum of a representative HRPIB sample prepared by the copolymerization isobutylene. The two protons characteristic of the exo-olefin end group (protons a1 and a2) appeared as two well resolved peaks at 4.85 and $4.64 \mathrm{ppm}$, respectively, while the endo olefin end group (proton d) appeared as a single peak at $5.15 \mathrm{ppm}$. Small amounts of the $E$ and $Z$ configurations of another tri-substituted olefin end group (proton e1 represents $Z$ configuration and proton e2 represents $E$ configuration) were also observed in some samples at 5.37 and $5.17 \mathrm{ppm}$. The signal corresponding to the tetra-substituted olefin end group (proton f) appeared as a broad multiplet at $2.85 \mathrm{ppm}$. The methine protons in the $\mathrm{PIB}-1 \mathrm{~B}-\mathrm{Cl}$ group (protons $-\mathrm{CHCl}-$ ) which appear at $3.95 \mathrm{ppm}$. Resonances for BD coupled PIB chains (protons BD1 and BD2) appeared at $4.82 \mathrm{ppm}$. The methylene and methyl protons of the isobutylene repeat unit (protons b and c, respectively) usually appeared at 1.42 and 1.11 ppm, respectively.

It has been shown that a complex set of isomerization is basis for the formation of different types of PIB terminal ends with 1B, C2B and BD units (Scheme 8). To explain the complex mechanism, low-temperature ${ }^{1} \mathrm{H}$ NMR studies were carried. As part of this the sec-alkyloxoniums were formed individually from the reaction of TMPCl with $\mathrm{B} 1$ or $\mathrm{C} 2 \mathrm{~B}$ or BD in the presence of EADC - CEE at $0{ }^{\circ} \mathrm{C}$. The NMR studies clearly support the proposed possible mechanistic pathways.

Very recently, the copolymerization of isobutylene in the presence of alcohol as an exo-enhancer with $t$-BuCl/EADC.CEE initiating system under simulated CSTR conditions has been investigated by Rajasekhar et al. ${ }^{54}$ The desired $M_{\mathrm{n}}(\sim 2200 \mathrm{~g}$ $\mathrm{mol}^{-1}$ ) and high exo content of HRPIB can be prepared only in 


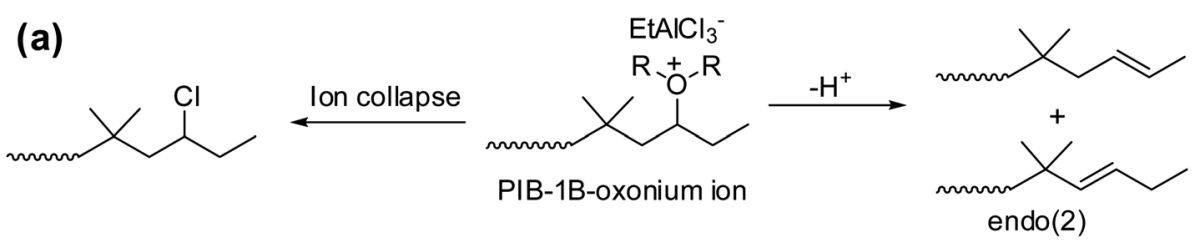

(b)
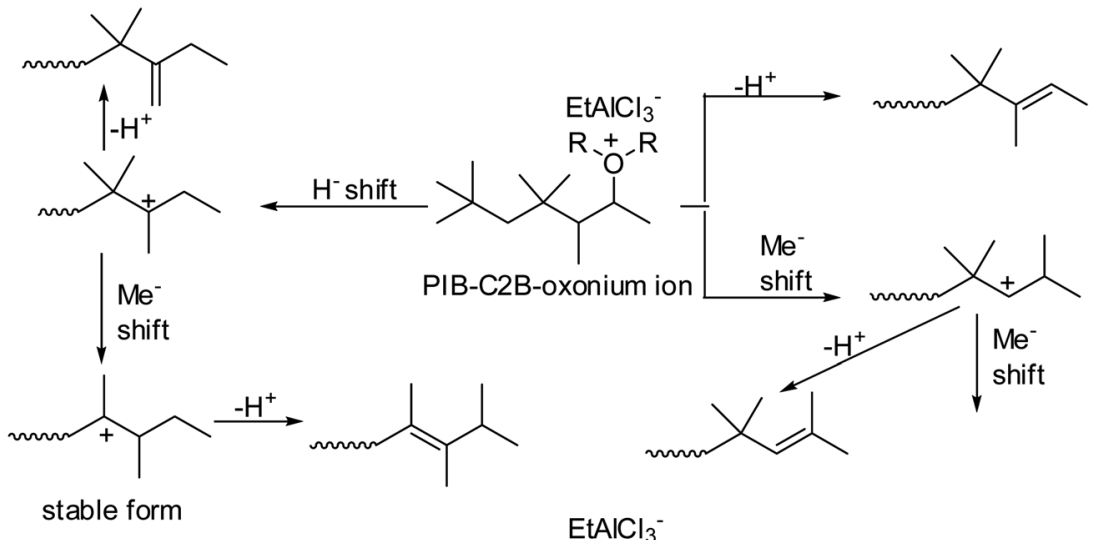

(c)

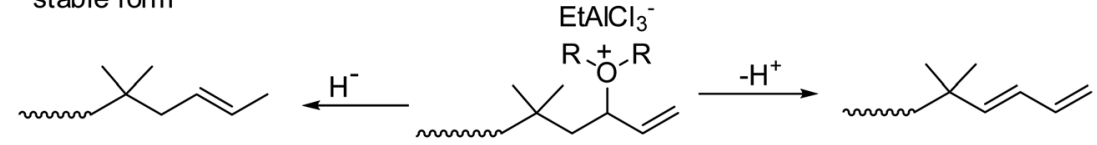

PIB-BD-oxonium ion

Scheme 8 Schematic representation of the sec-alkyloxonium ions, (a) PIB-1B-oxonium ion, (b) PIB-C2B-oxonium ion and (c) PIB-BD-oxonium ion, rearrangement on copolymerization of isobutylene using $\mathrm{EtAlCl}_{2} \cdot \mathrm{ROR}$ initiating system (proposed by Rajasekhar et al. ${ }^{50}$ ).

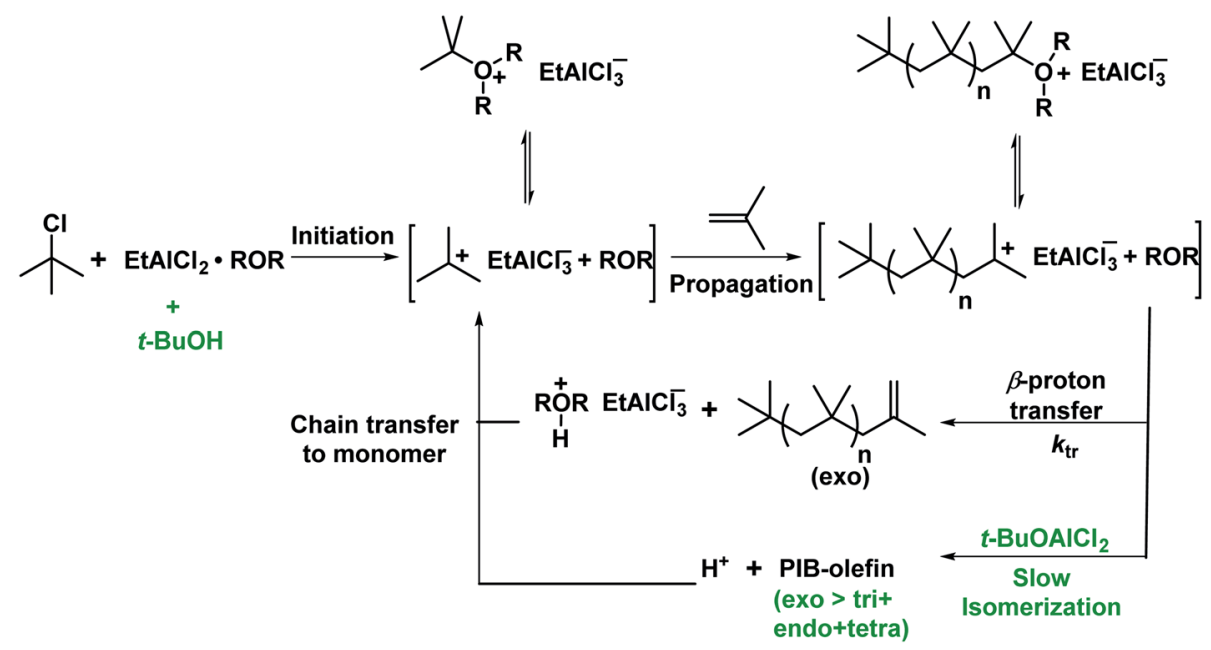

Scheme 9 Possible mechanism for polymerization of IB with $t$-BuCl/EADC.CEE in the presence of $t$-BuOH (proposed by Rajasekhar et al. ${ }^{54}$ ).

the presence of exo enhancer under the CSTR conditions. In the absence of exo enhancer, the desired molecular weight have been achieved only at $70-80 \%$ CSTR conversions at $0{ }^{\circ} \mathrm{C}$ with $[\mathrm{CEE}] /[\mathrm{EADC}]=1.5$ with exo content $\sim 80 \%$. But the desired molecular weight was achieved with high CSTR conversion (90$95 \%)$ at $[\mathrm{CEE}] /[\mathrm{EADC}]=1$. However, low $[\mathrm{CEE}]$ caused to decrease in exo content to $\sim 70 \%$. It means that [CEE]/[EADC] > 1 is necessary to maintain high exo content. In this report found that alcohols could be used as exo-enhancers, where the content of exo-olefin end groups increased with increasing bulkiness of the alkyl group of the alcohol in the following series: primary alcohol $<$ sec-alcohol < tert-alcohol. Molecular weights were virtually unaffected in the presence of exo enhancer with [CEE]/ $[\mathrm{EADC}]=1$. The real exo-enhancer in these polymerizations is alkoxyaluminum dichloride $\left(\mathrm{ROAlCl}_{2}\right)$, which could be formed in the polymerization mixture by the reaction of EADC.CEE with alcohol. Moreover, molecular weights have been almost unaffected in the presence exo enhancer, $\mathrm{ROAlCl}_{2}$ with $\left[\mathrm{ROAlCl}_{2}\right]:[\mathrm{EADC} \cdot \mathrm{CEE}]<0.5$, and exo-olefin content improved $15 \%$ in comparison to polymerization in the absence of exo- 
enhancer. The systematic experimental results discussed in this study suggest that $t$ - $\mathrm{BuOAlCl}_{2}$ suppressing the isomerization of $\mathrm{PIB}^{+}$, but does not act as a chain transfer agent, for the proposed mechanism (see Scheme 9). The increase of the exo content in the presence of exo-enhancer is attributed to the stabilization of $\mathrm{PIB}^{+}$by the enhancer. The stabilization of $\mathrm{PIB}^{+}$has been illustrated by a model study. In the model study, interaction of carbenium ion, $\mathrm{PhCH}_{2}{ }^{+}$and $t$ - $\mathrm{BuOAlCl}_{2}$ was studied using lowtemperature NMR spectroscopy. This is the original report that stabilization of carbocations in the cationic polymerization has also been proven, which opens new vistas in this area of research. From this report understood that $\mathrm{RAlCl}_{2} \cdot$ ether initiating systems in the presence of tert-alcohol are the best candidates to synthesize desired low molecular weight HRPIB with high exo-olefin end group content in non-polar solvent conditions.

Later on, Kostjuk et al., extended the study to cationic polymerization of isobutylene to produce HRPIB of low molecular weight ( $\sim 1000 \mathrm{~g} \mathrm{~mol}^{-1}$ ) to medium molecular weight (up to $50000 \mathrm{~g} \mathrm{~mol}^{-1}$ ) under mild experimental conditions using alkoxy aluminum chlorides as catalyst. From experimental observations, authors conclude that alkoxy aluminum chloride acts concurrently as co-initiator, carbocation stabilizer, and chain-transfer agent. ${ }^{\mathbf{1 3 4}}$

Overall, the specific merits of the recent developments in CCTP and their advantages over the traditional polymerization system show industrial interest. Recently developed approaches coupled with existed industrial approaches will give out to intensify the mechanistic understanding of CCTP and thus eventually help in the development of new ones.

\section{Conclusion}

In this review, we have discussed advances in the preparation of HRPIB using cationic polymerization of isobutylene. Following the development of CCTP about last few years, tremendous efforts have been made to explore new approaches for HRPIB. The CCTP has emerged as an extremely influential method, which is of vast industrial and fundamental importance. The recent rapid development in this area of research has been explored to new initiating systems in nonpolar solvents, LA- ether complexes in conjunction with cationogen, which are the best alternative systems in the place of traditional $\mathrm{BF}_{3}$ catalyzed process. Compare to the traditional catalyst system, LA· ether complexes significant advantage of highly selective for the more useful exo olefin end groups and the most suitable ambient reaction conditions. Moreover, this new initiating systems demonstrate significant efficiency for isobutylene/ industrial Raffinate-1 polymerization, which is also endowed with conceivable industrial importance for the synthesis of low molecular weight HRPIB. The kinetic and mechanistic aspects can attribute to make the way for creating rules for the reasonable selection of reaction conditions to achieve the synthesis of the targeted PIB precursors, HRPIB. Furthermore, due to these recent accomplishments in economic way of synthesis of HRPIB, advance industrial developments are expected.

\section{Conflicts of interest}

There are no conflicts to declare.

\section{References}

1 R. M. Mortier, F. F. Malcolm and S. T. Orszulik, Chemistry and Technology of Lubricants, Springer, London, 2009.

2 S. Q. A. Rizvi, Additives and additive chemistry, fuels and lubricants: technology, properties, performance, and testing, ASTM International, West Conshohocken, PA, 2003, p. 199.

3 W. M. Le Suer and G. R. Norman, US Pat., US3172892A, 1965.

4 A. F. Stuart, R. G. Orinda, N. Anderson and A. Y. Drummond, US Pat., US3202678, 1965.

5 H. Mach and P. Rath, Lubr. Sci., 1999, 175, 11.

6 J. J. Harrison, C. M. Mijares, M. T. Cheng and J. Hudson, Macromolecules, 2002, 35, 2494.

7 I. Puskas and S. Meyerson, J. Org. Chem., 1984, 49, 258.

8 F. Balzano, A. Pucci, R. Rausa and G. Uccello-Barretta, Polym. Int., 2012, 61, 1256-1262.

9 I. Puskas, E. M. Banas and A. G. Nerheim, J. Polym. Sci., Polym. Symp., 1976, 56, 191-202.

10 F. Balzano, A. Pucci, R. Rausa and G. Uccello-Barretta, Polym. Int., 2012, 61, 1256-1262.

11 I. Puskas, E. M. Banas and A. G. Nerheim, J. Polym. Sci., Polym. Symp., 1976, 56, 91-202.

12 I. Puskas and S. J. Meyerson, Org. Chem., 1984, 49, 258.

13 J. J. Harrison, C. M. Mijares, M. T. Cheng and J. Hudson, Macromolecules, 2002, 35, 2494.

14 J. P. Kennedy, V. S. C. Chang, R. A. Smith and B. Ivan, Polym. Bull., 1979, 1, 575.

15 J. P. Kennedy and R. A. Smith, J. Polym. Sci., Polym. Chem. Ed., 1980, 18, 1523.

16 B. Ivan and J. P. Kennedy, Macromolecules, 1990, 23, 2880.

17 M. K. Mishra, B. Sar-Mishra and J. P. Kennedy, Polym. Bull., 1985, 13, 435.

18 S. Zhu, Y. C. Lu, K. Wang and G. S. Luo, Eur. Polym. J., 2016, 80, 219.

19 S. Zhu, Y. C. Lu, K. Wang and G. S. Luo, RSC Adv., 2016, 6, 97983.

20 S. Ummadisetty, D. L. Morgan, C. D. Stokes and R. F. Storey, Macromolecules, 2011, 44, 7901.

21 S. Ummadisetty, D. L. Morgan, C. D. Stokes, J. J. Harrison, C. G. Campbell and R. F. Storey, Macromol. Symp., 2013, 323, 6 .

22 S. Ummadisetty and R. F. Storey, Macromolecules, 2013, 46, 2049.

23 M. R. Lichtenthaler, A. Higelin, A. Kraft, S. Hughes, A. Steffani, D. A. Plattner, J. M. Slattery and I. Krossing, Organometallics, 2013, 32, 6725.

24 A. K. Hijazi, N. Radhakrishnan, K. R. Jain, E. Herdtweck, O. Nuyken, H.-M. Walter, P. Hanefeld, B. Voit and F. E. Kühn, Angew. Chem., Int. Ed., 2007, 46, 7290.

25 N. Radhakrishnan, A. K. Hijazi, H. Komber, B. Voit, S. Zschoche, F. E. Kühn, O. Nuyken, M. Walter and 
P. Hanefeld, J. Polym. Sci., Part A: Polym. Chem., 2007, 45, 5636.

26 H. Y. Yeong, Y. Li, F. E. Kühn and B. Voit, J. Polym. Sci., Part A: Polym. Chem., 2013, 51, 158.

27 R. Kumar, B. Zheng, K.-W. Huang, J. Emert and R. Faust, Macromolecules, 2014, 47, 1959.

28 I. V. Vasilenko, D. I. Shiman and S. V. Kostjuk, Polym. Chem., 2014, 5, 3855.

29 D. I. Shiman, I. V. Vasilenko and S. V. Kostjuk, J. Polym. Sci., Part A: Polym. Chem., 2014, 52, 2386.

30 S. Banerjee, J. Emert, P. Wright, T. Skourlis, R. Severt and R. Faust, Polym. Chem., 2015, 6, 4902.

31 S. Banerjee, B. N. Jha, P. De, J. Emert and R. Faust, Macromolecules, 2015, 48, 5474.

32 D. I. Shiman, I. V. Vasilenko and S. V. Kostjuk, Polymer, 2016, 99, 633.

33 I. V. Vasilenko, P. A. Nikishev, D. I. Shiman and S. V. Kostjuk, Polym. Chem., 2017, 8, 1417.

34 T. Rajasekhar, J. Emert and R. Faust, Polym. Chem., 2017, 8, 2852.

35 S. Zhu, Y. Lu and R. Faust, RSC Adv., 2017, 7, 27629.

36 Q. Liu, Y.-X. Wu, Y. Zhang, P.-F. Yan and R.-W. Xu, Polymer, 2010, 51, 5960.

37 Q. Liu, Y. Wu, P. Yan, Y. Zhang and R. Xu, Macromolecules, 2011, 44, 1866.

38 I. V. Vasilenko, A. N. Frolov and S. V. Kostjuk, Macromolecules, 2010, 43, 5503.

39 I. V. Vasilenko, D. I. Shiman and S. V. Kostjuk, J. Polym. Sci., Part A: Polym. Chem., 2012, 50, 750.

40 P. Dimitrov, J. Emert and R. Faust, Macromolecules, 2012, 45, 3318.

41 R. Kumar, P. Dimitrov, K. J. Bartelson, J. Emert and R. Faust, Macromolecules, 2012, 45, 8598.

42 K. J. Bartelson, P. De, R. Kumar, J. Emert and R. Faust, Polymer, 2013, 54, 4858.

43 D. I. Shiman, I. V. Vasilenko and S. V. Kostjuk, Polymer, 2013, 54, 2235.

44 R. Kumar, P. De, B. Zheng, K.-W. Huang, J. Emert and R. Faust, Polym. Chem., 2015, 6, 322.

45 R. Kumar, J. Emert and R. Faust, Polym. Bull., 2015, 72, 49.

46 S. Zhu, Y. C. Lu, K. Wang and G. S. Luo, RSC Adv., 2016, 6, 9827.

47 T. Rajasekhar, U. Haldar, J. Emert, P. Dimitrov, R. Severt and R. Faust, J. Polym. Sci., Part A: Polym. Chem., 2017, 22, 3697.

48 I. V. Vasilenko, I. A. Berezianko, D. I. Shiman and S. V. Kostjuk, Polym. Chem., 2016, 7, 5615-5619.

49 I. A. Berezianko, I. V. Vasilenko, D. I. Shiman and S. V. Kostjuk, Polymer, 2018, 145, 382.

50 T. Rajasekhar, U. Haldar, P. De, J. Emert and R. Faust, Macromolecules, 2017, 50, 8325.

51 H. P. Rath, U. Kanne and F. V. Deyck, US Pat., US6407186B1, 2002.

52 H. P. Rath, US Pat., US5962604A, 1999.

53 S. Zhu, Y. Lu and R. Faust, RSC Adv., 2017, 7, 27629.

54 T. Rajasekhar, J. Emert, L. M. Wolf and R. Faust, Macromolecules, 2018, 51, 3041.
55 S. V. Kostjuk, RSC Adv., 2015, 5, 13125.

56 S. V. Kostjuk, I. V. Vasilenko, D. I. Shiman, A. N. Frolov and L. V. Gaponik, Macromol. Symp., 2015, 349, 94.

57 Y. Li, M. Cokoja and F. E. Kühn, Coord. Chem. Rev., 2011, 255, 1541.

58 S. V. Kostjuk, H. Y. Yeong and B. Voit, J. Polym. Sci., Part A: Polym. Chem., 2013, 51, 471.

59 J. E. Puskas and G. Kaszas, Prog. Polym. Sci., 2000, 25, 403.

60 R. Faust, Cationic polymerization of nonpolar vinyl monomers, in Polymer Science: A Comprehensive Reference, ed. K. Matyjaszewski and M. Möller, Elsevier, 2012, vol. 3, pp. 501-526.

$61 \mathrm{~J} . \quad$ P. Kennedy and E. Marechal, Carbocationic Polymerization, Wiley, New York, 1982.

62 I. Puskas and S. Meyerson, J. Org. Chem., 1984, 49, 258.

63 J. J. Harrison, C. M. Mijares, M. T. Cheng and J. Hudson, Macromolecules, 2002, 35, 2494.

64 J. J. Harrison, D. C. Young and C. L. Mayne, J. Org. Chem., 1997, 62, 693.

65 P. Dimitrov, J. Emert, J. Hua, S. Keki and R. Faust, Macromolecules, 2011, 44, 1831.

66 H. P. Rath, US Pat., 5286823, BASF AG, 1994.

67 H. P. Rath, F. Hoffmann, P. Reuter and H. Mach, US Pat., US5191044, 1993.

68 S. Aoshima and S. Kanaoka, Chem. Rev., 2009, 109, 5245.

69 D. C. Pepper, in Friedel-Crafts and Related Reactions, ed. G. A. Olah, Interscience, New York, 1964, ch. 30.

70 J. P. Kennedy, Cationic Polymerization of Olefins: A Critical InVentory, John Wiley and Sons, New York, 1975.

71 G. Odian, Principles of Polymerization, Wiley Interscience, 2004, ISBN: 978-0-471-27400-1.

72 G. A. Mortimer and L. C. Arnold, J. Polym. Sci., Part A: Gen. Pap., 1964, 2, 4247.

73 R. Faust and J. P. Kennedy, Polym. Bull., 1986, 15, 317.

74 M. Miyamoto, M. Sawamoto and T. Higashimura, Macromolecules, 1984, 17, 265.

75 M. Miyamoto, M. Sawamoto and T. Higashimura, Macromolecules, 1984, 17, 2228.

76 Cationic Polymerizations: Mechanism, Synthesis, and Applications, ed. K. Matyjaszewski, Marcel Dekker, New York, 1996.

77 R. Faust and J. P. Kennedy, J. Polym. Sci., Part A: Polym. Chem., 1987, 25, 1847.

78 M. Sawamoto, Prog. Polym. Sci., 1991, 16, 111.

79 J. P. Kennedy and B. Iván, Designed Polymers by Carbocationic Macromolecular Engineering: Theory and Practice, Oxford University Press, New York, 1992.

80 P. Sigwalt, Some still unsolved problems in carbocationic polymerization, Macromol. Symp., 1998, 132, 127.

$81 \mathrm{H}$. Mayr, in Ionic Polymerizations and Related Processes; NATO Science Series E, ed. J. E. Puskas, Kluwer Academic Publishers, Dordrecht/Boston/London, 1999, vol. 359, p. 99.

82 D. Cook, Infrared spectra of xanthone: Lewis acid complexes, Can. J. Chem., 1963, 41, 522.

83 J. P. Kennedy and B. Iván, Designed Polymers by Carbocationic Macromolecular Engineering, Hanser Publishers, Munich, Vienna, New York, Barcelona, 1991. 
84 Z. S. Fodor and R. Faust, J. Macromol. Sci., Part A: Pure Appl.Chem., 1998, 35(2), 375.

85 R. M. Thomas, I. E. Lightbown, W. J. Sparks, K. P. Frolich and E. L. Murphree, Ind. Eng. Chem., 1940, 32, 1283.

86 R. M. Thomas, W. J. Sparks, P. K. Frolich and M. Otto, J. Am. Chem. Soc., 1940, 62, 276.

87 R. M. Thomas and W. J. Sparks, US Pat., US2356128, 1944.

88 R. Faust and J. P. Kennedy, J. Polym. Sci., Part A: Polym. Chem., 1986, 25, 1847.

89 S. Ouardad, A. Deffieux and F. Peruch, Pure Appl. Chem., 2012, 84, 2065.

90 V. A. Rozentsvet, V. G. Kozlov and Y. B. Monakov, Cationic Polymerization of conjugated dienes, Nauka, Moscow, 2011.

91 S. Ouardad, M.-E. Bakleh, S. V. Kostjuk, F. Ganachaud, J. E. Puskas, A. Deffieux and F. Peruch, Polym. Int., 2012, 61, 149.

92 J. J. Harrison, D. C. Young and C. L. Mayne, J. Org. Chem., 1997, 62, 693.

93 M. Mueller-Cunradi and M. Otto, US Pat., US2203873, 1940.

94 E. J. Goethals and F. Du Prez, Prog. Polym. Sci., 2007, 32, 220.

95 S. Penczek, Makromol. Chem., Rapid Commun., 1992, 13, 147.

96 T. Pernecker, J. P. Kennedy and B. Iván, Macromolecules, 1992, 25, 1642.

97 T. Pernecker and J. P. Kennedy, Polym. Bull., 1992, 29, 27.

98 M. Kamigaito, Y. Maeda, M. Sawamoto and T. Higashimura, Macromolecules, 1993, 26, 1643.

99 J. V. Crivello and K. Dietliker, Photoinitiators for Free Radical Cationic and Anionic Photopolymerization, ed. G. Bradley, Wiley, New York, 1998, p. 53.

100 J. V. Crivello, Des. Monomers Polym., 2002, 5, 141.

101 C. C. Chen, J. Si and J. P. Kennedy, J. Macromol. Sci., Part A: Pure Appl.Chem., 1992, 29, 669.

102 J. E. Puskas and M. Grassmuller, Makromol. Chem., Macromol. Symp., 1998, 132, 117.

103 B. Rajabalitar, H. A. Nguyen and H. Cheradame, Macromolecules, 1996, 29, 514.

104 M. Bahadur, T. D. Shaffer and J. R. Ashbaugh, Macromolecules, 2000, 33, 9548.

105 S. Hadjikyriacou, M. Acar and R. Faust, Macromolecules, 2004, 37, 7543.

106 J. P. Kennedy, V. S. C. Chang, R. A. Smith and B. Ivan, Polym. Bull., 1979, 1, 575.

107 J. P. Kennedy and R. A. Smith, J. Polym. Sci., Polym. Chem. Ed., 1980, 18, 1523.

108 M. K. Mishra, B. Sar-Mishra and J. P. Kennedy, Polym. Bull., 1985, 13, 435.

109 B. Ivan and J. P. Kennedy, Macromolecules, 1990, 23, 2880. 110 L. Wilczek and J. P. Kennedy, Polym. Bull., 1987, 17, 37.
111 L. Wilczek and J. P. Kennedy, J. Polym. Sci., Part A: Polym. Chem., 1987, 25, 3255.

112 B. Ivan and J. P. Kennedy, Polym. Mater. Sci. Eng., 1988, 58, 869.

113 B. Ivan and J. P. Kennedy, J. Polym. Sci., Part A: Polym. Chem., 1990, 28, 89.

114 L. V. Nielsen, R. R. Nielsen, B. Gao, J. Kops and B. Ivan, Polymer, 1997, 38, 2529.

115 M. Roth and H. Mayr, Macromolecules, 1996, 29, 6104.

116 L. K. Kemp, J. E. Poelma, T. R. Cooper and R. F. Storey, J. Macromol. Sci., Part A: Pure Appl.Chem., 2008, 45, 137.

117 K. L. Simison, C. D. Stokes, J. J. Harrison and R. F. Storey, Macromolecules, 2006, 39, 2481.

118 D. Held, B. Ivan, A. H. E. Müller, F. de Jong and T. Graafland, ACS Symp. Ser., 1997, 665, 63.

119 Y. C. Bae and R. Faust, Macromolecules, 1997, 30, 7341.

120 M. Vierle, Y. Zhang, E. Herdtweck, M. Bohnenpoll, O. Nuyken and F. E. Kühn, Angew. Chem., Int. Ed., 2003, 42, 1307.

121 A. Guerrero, K. Kulbaba and M. Bochmann, Macromolecules, 2007, 40, 4124.

122 A. K. Hijazi, N. Radhakrishnan, K. R. Jain, E. Herdtweck, O. Nuyken, H.-M. Walter, P. Hanefeld, B. Voit and F. E. Kühn, Angew. Chem., Int. Ed., 2007, 46, 7290.

123 M. R. Lichtenthaler, A. Higelin, A. Kraft, S. Hughes, A. Steffani, D. A. Plattner, J. M. Slattery and I. Krossing, Organometallics, 2013, 32, 6725.

124 H. Y. Yeong, Y. Li, F. E. Kühn and B. Voit, J. Polym. Sci., Part A: Polym. Chem., 2013, 51, 158-167.

125 S. V. Kostjuk, F. N. Kaputsky, V. P. Mardykin, L. V. Gaponik and L. M. Antipin, Polym. Bull., 2002, 49, 251.

126 S. V. Kostjuk, Polym. Bull., 2004, 51, 277.

127 S. V. Kostjuk, A. Yu. Dubovik, I. V. Vasilenko, A. N. Frolov and F. N. Kaputsky, Eur. Polym. J., 2007, 43, 968.

128 A. N. Frolov, S. V. Kostjuk, I. V. Vasilenko and F. N. Kaputsky, J. Polym. Sci., Part A: Polym. Chem., 2010, 48, 3736.

129 P. W. Ambler, P. K. G. Hodgson and N. J. Stewart, EP 0558187, BP Chem. Ltd, 1993.

130 A. Abdul-Sada, P. W. Ambler, P. K. G. Hodgson, K. R. Seddon and N. J. Stewart, WO 9521871, BP Chem. Ltd, 1995.

131 V. Murphy, WO 00/32685, Symyx Tech. Inc., 2000.

132 A. Abdul-Sada, K. P. Seddon and N. J. Stewart, WO 9521872, BP Chem. Ltd, 1995.

133 X. Li, Y. Wu, J. Zhang, S. Li, M. Zhang, D. Yang, H. Wang, Y. Shang, W. Guo and P. Yan, Polym. Chem., 2019, 10, 201.

134 D. I. Shiman, I. V. Vasilenko and S. V. Kostjuk, Polym. Chem., 2019, 10, 5998. 